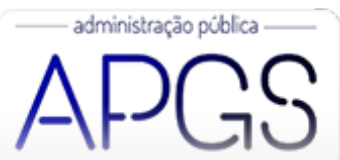

Administração Pública e Gestão Social ISSN: 2175-5787

apgs@ufv.br

Universidade Federal de Viçosa

Brasil

\title{
As variáveis para uma gestão de contratos eficiente: o caso de uma empresa pública federal
}

Fernandes Modesto de Oliveira, Wanderson; José Guerra Leone, Rodrigo; Amaral de Souza, Lieda As variáveis para uma gestão de contratos eficiente: o caso de uma empresa pública federal

Administração Pública e Gestão Social, vol. 12, núm. 2, 2020

Universidade Federal de Viçosa, Brasil

Disponible en: http://www.redalyc.org/articulo.oa?id=351562414002

Esta obra está bajo una Licencia Creative Commons Atribución-NoComercial-SinDerivar 3.0 Internacional. 


\title{
As variáveis para uma gestão de contratos eficiente: o caso de uma empresa pública federal
}

\author{
The variables for an efficient contract management: The case of a federal state enterprise \\ Variables para una gestión de contratos eficiente: El caso de una empresa pública federal \\ Wanderson Fernandes Modesto de Oliveira \\ Universidade Potiguar, Brasil \\ Redalyc: http://www.redalyc.org/articulo.oa? \\ wandersonf81@gmail.com \\ id $=351562414002$
}

Rodrigo José Guerra Leone

Universidade Potiguar, Brasil

prof.rodrigoleone@gmail.com

\section{Lieda Amaral de Souza \\ Faculdade BSSP, Brasil \\ lieda2009@gmail.com}

Recepción: 26 Septiembre 2017

Aprobación: 02 Abril 2019

Publicación: 01 Abril 2020

\section{Resumo:}

Este trabalho tem por objetivo identificar variáveis relacionadas a uma eficiente gestão de contratos que conduzem uma empresa pública à redução de custos e à melhoria da qualidade dos serviços prestados pelas empresas por ela contratadas. Para tanto, foi feita uma pesquisa descritiva e qualitativa em que os dados foram coletados por meio de entrevistas em profundidade com gestores de contratos de cinco regionais da empresa pública objeto deste estudo e tratados por análise de conteúdo, utilizando o software NVivo11. Os resultados apontaram a existência de nove variáveis específicas da atividade ainda não referenciadas na literatura, sendo as principais: (i) Controle da vigência dos contratos, (ii) cumprimento do prazo de tramitação do processo de elaboração dos termos aditivos, e (iii) controle da regularidade da documentação do processo para emissão de um termo aditivo. Conclui-se que a gestão de contratos da Administração Pública pode conduzir à redução de custos com a contratação e com a execução do contrato com a empresa contratada e também à melhoria da qualidade do serviço que lhe é prestado, por meio dessas três novas variáveis encontradas.

Palavras-Chave: Administração pública, Gestão de contratos, Redução de custos, Qualidade de serviços, Empresas contratadas.

\section{Resumen:}

Esta investigación tiene por objetivo identificar variables relacionadas a una eficiente gestión de contratos que conducen una empresa pública a la reducción de costes y a la mejora de la calidad de los servicios otorgados por las empresas privadas contratadas. Para ello, se realizó una investigación exploratoria y cualitativa, los datos recolectados son oriundos de entrevistas en profundidad con gestores de contratos de las cinco regiones de la empresa pública objeto del estudio y tratados por análisis de contenido, utilizando el software NVivo1 1. Los resultados han mostrado la existencia de nueve variables específicas de la actividad aún no referenciadas en la literatura, siendo las principales: Control de vigencia de los contratos, cumplimiento del plazo de tramitación del proceso de elaboración de los términos aditivos y control de la regularidad de la documentación del proceso para emisión de un término aditivo. Se concluye que la gestión de los contratos de la administración pública puede conducir a la reducción de costos con la contratación y con la ejecución del contrato con el contratista y también a la mejora de la calidad del servicio que se proporciona, a través de estas tres nuevas variables encontradas.

Palabras clave: Administración pública, Gestión de contratos, Reducción de costes, Cualidad de servicios, Empresas contratadas.

\section{Abstract:}


This work aims to identify variables related to an efficient contract management leading a public company to reduce costs and to improve the quality of the services that are provided by contractors. An exploratory and qualitative researchwas made, in which the notes were collected by in-depth interviews with five regional contract managers from the public company that is the object of the study. These interviews were treated by content analysis, using the NVivol1 software. The results showed the existence of nine specific activity variables not yet referenced in literature, being the main ones the control of the duration of contracts, the compliance with the time limit for handling the process of preparation of addenda and the control of the regularity of the documentation of the process for issuance of an additive term. It is concluded that the contract management of Public Administration may lead to cost reduction with the hiring and with the execution of the contract with the contractor and also to the improvement of the quality of service that is provided, through these three new variables.

KEYWORDS: Public management, Contract management, Cost reduction, Quality of services, Contracted companies.

\section{INTRODUÇÃO}

O movimento conhecido como New Public Management (NPM) introduziu, na década de 1980, uma nova onda de técnicas de gestão no setor público e foi delineada com a incorporação no mundo dos governos dos princípios de mercado, tendo como justificativa o fato de que elas são necessárias para melhorar o desempenho do governo e da prestação de contas à sociedade (Rkein \& Andrew, 2012).

Nesta perspectiva, a adoção das práticas de gestão de empresas privadas (que inclui a busca pela eficiência) em organizações públicas foi, segundo Guerra et al. (2012), decorrente de quatro grandes tendências mundiais: A paralisação ou redução no crescimento do Estado, a terceirização e privatização de serviços oferecidos pelo Estado, a adoção por parte do Estado das tecnologias de informação e a cooperação entre os países a fim de dividir uma agenda pública comum e que levou a administração pública a buscar ser mais ágil e flexível para dar uma resposta à sociedade, a qual começava a cobrar dos administradores públicos uma maior eficiência nos gastos e um melhor resultado gerencial (Motta, 2013).

No cenário brasileiro, as atividades administrativas e operacionais dos órgãos públicos são regidas por leis e por normas internas. Para executar o seu plano de governo, o Estado depende da aquisição de bens e serviços necessários às suas atividades. Diferentemente das empresas privadas, que podem escolher livremente o que adquirir, a Administração Pública deve seguir procedimentos definidos em lei para a compra de todos os insumos necessários (Camargos \& Moreira, 2015). Neste contexto, os princípios da Administração Pública, estabelecidos no art. 37 da Constituição Federal de 1988, legalidade, impessoalidade, moralidade, publicidade e eficiência (Constituição da República Federativa do Brasil de 1988, 2014), a Lei $8.666^{[1]}$, de 21/06/1993, conhecida como a "Lei de Licitações e Contratos Administrativos" e a Lei 10.520, de 17/07/2002, a "Lei do Pregão", são alguns dos marcos jurídicos regulatórios que delineiam todos os processos da gestão de contratos e de licitações em empresas públicas (Mendes \& Biasi, 2011).

De acordo com Motta (2011), antes da criação da Lei 8.666/93, a legislação em vigor era datada de 21 de novembro de 1986, sob o Decreto-lei 2.300. Com o nascimento da Lei 8.666 criou-se um meio de regramento dos processos licitatórios, mas antes ainda, observou-se o Projeto de Lei 1.491 de 07 de agosto de 1991. A sanção da lei no ano de 1993, não estancou a criação de novas medidas provisórias no período de 1994 até 1998, quando a sanção da Lei 9.648/98 alterou 11 artigos da Lei 8.666/93. Em 1999, a Lei 8.666/93 absorveu ainda os dizeres da Lei 9.854/99, acrescendo o inciso V ao art. 27 e o inciso XVIII ao art. 78.

$\mathrm{Na}$ evolução da relação entre a Administração Pública e as empresas contratadas, para a compra de bens e contratação de serviços, Medeiros et al. (2014) comentam que dentre as modificações relevantes para com a Lei $\mathrm{n}^{\circ} 8.666 / 93$, ocorreram diversos decretos, como o de $\mathrm{n}^{\circ} 3.784 / 01$, referente à modalidade pregão, que não fazia parte da Lei $n^{\circ} 8.666 / 1993$. Posteriormente, com a Lei $n^{\circ} 10.520 / 02$, veio a ser estabelecido o pregão como modalidade de licitação e, em 2005, o Decreto no 5.450 instituiu a utilização do Pregão Eletrônico. Persson et al. (2016) acrescentam outras modificações, tais como o sistema de registro de preços, com os Decretos $n^{\circ} 3.931 / 01$ e $n^{\circ} 7.892 / 13$, das normas relativas às licitações sustentáveis e do novo regramento para licitações de publicidade. O Regime Diferenciado de Contratações Públicas (RDC) surge com a Lei no 
12.462/11, e posteriores alterações, regulamentada pelos Decretos $n^{\circ} 7.581 / 11, n^{\circ} 8.080 / 13$ e $n^{\circ} 8.251 / 14$, como alternativa para viabilizar a realização dos procedimentos licitatórios necessários às contratações dos eventos da Copa do Mundo de 2014 e das Olimpíadas de 2016. Em sua essência, o RDC visa tornar mais ágeis e céleres as licitações e obter maior eficácia e eficiência nos contratos públicos (Medauar, 2015).

Conforme Cintra et al. (2012), o contrato administrativo é o instrumento que a administração pública utiliza para formalizar a contratação com terceiros, com o objetivo de atender seus objetivos de modo eficiente. $\mathrm{O}$ foco da gestão de contratos remete principalmente ao resultado do processo de compra e o gestor de contratos na Administração deve estar munido do instrumental necessário ao adequado acompanhamento do processo de fornecimento da compra (Andrade, 2010).

Nessa perspectiva de resultado das compras governamentais, o trabalho de Lewis e Bajari (2011) aponta que nos contratos públicos, o bem-estar social geralmente depende da rapidez com que o bem é entregue ou o serviço é prestado. Por isso, no modelo de gestão que os autores apresentam no seu artigo é proposto que as áreas de contratação dos órgãos públicos elaborem contratos usando leilóes de pontuação, que dão aos contratados incentivos explícitos para uma entrega mais rápida.

Pesquisas anteriores sugerem que uma eficiente gestão de contratos poderá influenciar na redução dos custos e na melhoria da qualidade dos serviços prestados e dos bens produzidos (Franco et al., 2011; Vila, 2010). Faria et al. (2010) estudaram as causas determinantes da variação de preços dos produtos comprados por meio de pregão eletrônico e os resultados sugerem que as variáveis "número de fornecedores", "especificidade dos ativos" "quantidade" e "frequência das transações" possuem poder de explicação de 67,4\% das variações dos preços. Medeiros et al. (2014) avaliaram a qualidade de produtos e de serviços comprados em licitações na Câmara de Vereadores no Rio Grande do Sul e constatou-se que, de um modo geral, a qualidade dos produtos é satisfatória. Jorge et al. (2010), tendo por objeto um instituto público, aferiram a relação entre as diversas modalidade de compras com os custos finais dessas compras e os resultados evidenciaram a redução dos custos, quando ocorre a ampliação de concorrência nas licitações.

Contudo, observou-se uma lacuna nessas pesquisas, pois elas não abordam a relação entre a gestão de contratos de um órgão público (com as empresas contratadas para lhe prestarem serviços) e suas influências na redução de custos com a contratação e com a execução do contrato e na melhoria da qualidade dos serviços contratados. Além do mais, acrescenta-se o fato de não ter sido encontrado nos periódicos da base de pesquisa consultada: Academic Search Elite, Emerald, ProQuest, Scopus, Scielo, ScienceDirect e SPELL, no período de 2000 a $2017^{[2]}$, artigos que tratem dessa relação.

Portanto, este artigo buscou identificar as variáveis relacionadas à gestão de contratos, que levam uma organização pública à redução dos custos com a contratação, com a execução do contrato firmado e à melhoria da qualidade dos serviços prestados pelas empresas contratadas à contratante.

A relevância deste artigo está na abordagem de um tema que tem impacto social, uma vez que, quando a Administração Pública consegue reduzir custos com as empresas que lhes prestam serviços e, ao mesmo tempo, a qualidade desses serviços é melhorada, a sociedade é beneficiada, principalmente em um cenário de aguda crise financeira que tem afetado os órgãos dos três níveis de governo no Brasil, os quais têm anunciado a intenção de implementar iniciativas visando à redução de despesas, ao mesmo tempo em que tentam atender as demandas da sociedade com serviços de melhor qualidade, para tanto, como será apresentado a seguir, a gestão eficiente de contratos com empresas terceirizadas poderá contribuir para que a Administração Pública possa, de acordo com sua realidade, alcançar essa finalidade.

O trabalho é formado pelas seguintes seções: Introdução; referencial teórico, na qual são apresentados os temas relacionados à gestão de contratos em empresas públicas, à gestão de custos no setor público e à qualidade de serviço; análise dos resultados e considerações finais. 


\section{REFERENCIAL TEÓRICO}

\subsection{A gestão de contratos na Administração Pública no Brasil}

$\mathrm{Na}$ relação contratual entre empresas privadas e públicas, com o objetivo de atender aos interesses do governo, Girth (2014) entende que a mesma é acordada por meio de parcerias e que geralmente são formalizadas com a finalidade de alguma combinação de serviços, construção ou financiamento em troca de alguma combinação de fundos públicos, ativos públicos ou taxas de uso. Essas parcerias inerentemente requerem cooperação e sinergia entre os colaboradores para o desenvolvimento e (ou) entrega de um projeto ou serviço. Para Freitas e Maldonado (2013), as contratações de serviços e as aquisições de bens pela Administração Pública, devem ser feitas mediante procedimento licitatório, para que seja selecionada a proposta mais vantajosa para a Administração. A Lei no 8.666/1993 e o Decreto no 5.450/2005 são os principais dispositivos legais que disciplinam as licitações públicas e a gestão dos contratos firmados (Freitas \& Maldonado, 2013; Mendes \& Biasi, 2011). Sharf e Soriano-Sierra (2006) explicam que, de acordo com a Lei no 8.666/93, as licitações podem ser realizadas nas modalidades de Concorrência, Tomada de Preço, Convite, Concurso, Leilão e Pregão, e que, como regra, o critério de seleção da modalidade é o econômico.

No entendimento de Gouvêa et al. (2015), é crucial para a Administração Pública o planejamento das etapas em um processo de compra de bens ou para contratação de serviços. Em uma primeira etapa, é elaborado o projeto contendo todas as características técnicas do objeto a ser contratado (tipo, quantidade, dimensões, locais de entrega ou da prestação do serviço, dias, horários, frequência, dentre outras); numa segunda etapa, planeja-se a realização da licitação; em seguida, para a contratação da empresa vencedora do certame licitatório e, após a assinatura do contrato, para realizar o acompanhamento da execução do contrato (por meio do gestor do contrato), fiscalizando se o bem a ser entregue ou o serviço está sendo prestado conforme as cláusulas contratuais, realizando os pagamentos e, se for o caso, notificando e multando, quando a contratada comete erros graves na prestação do serviço ou na entrega do bem comprado (Krammes, 2013; Silveira et al., 2012).

Cintra et al. (2012) destacam que o contrato administrativo é o instrumento que a Administração Pública utiliza para formalizar a contratação com terceiros, com o objetivo de atender seus interesses e todo contrato é regido por normas do ramo do direito público, para originar obrigações e direitos comuns. As alterações contratuais são formalizadas por intermédio do instrumento denominado de aditamento contratual, cuja finalidade específica é regularizar alterações feitas no contrato original, tais como o aumento (ou a diminuição) da quantidade contratada, prorrogação da vigência, repactuação e reajuste do valor dos serviços, dentre outras que estejam previstas no contrato (Minuzzi-Nascimento \& Tomaél, 2012).

Vieira (2014) afirma que a gestão de contratos diz respeito aos aspectos inerentes à elaboração dos contratos administrativos, quanto à definição do objeto a ser contratado; à observância da vigência; às eventuais possibilidades ou necessidades de alterações contratuais; às possibilidades de reajuste, repactuação e reequilíbrio econômico e financeiro e à execução contratual propriamente dita, fundadas nas cláusulas contratuais, tendo como perspectivas norteadoras a vantajosidade para a Administração Pública e o atendimento eficiente da demanda da sociedade, mas no arcabouço da lei.

Nessa linha, Santilli et al. (2011) sugerem as seguintes práticas para uma eficiente gestão de contratos: (1) Realizar uma pré-licitação, para determinar quais produtos/serviços serão adquiridos; (2) elaborar uma padronização da forma de avaliação dos serviços; (3) estabelecer um catálogo de preços para os serviços prestados, de forma que seja possível negociar e estabelecer um limite para os custos com fornecedores; (4) envolver todas as expertises necessárias para uma análise correta das propostas dos fornecedores, e (5) monitorar a utilização do serviço para constantemente avaliar se o mesmo está sendo executado de acordo com o contrato. 
A Tabela 1 sintetiza as dimensões do constructo gestão de contratos e as variáveis relacionadas identificadas na literatura. Elas representam objetivos que a gestão de contratos de uma empresa pública deve alcançar para ser eficiente em sua gestão com as contratadas que lhes prestam serviços. (Error 1: La referencia: Tabela 1 está ligada a un elemento que ya no existe)

Tabela 1 Variáveis adaptadas de gestão de contratos para o setor público.

\begin{tabular}{|c|c|c|c|}
\hline Construto & Dimensões & Variáveis & Referências \\
\hline \multirow{6}{*}{$\begin{array}{l}\text { Gestão de } \\
\text { contratos }\end{array}$} & Aditivo & $\begin{array}{l}\text { São os aditivos aos contratos } \\
\text { referentes ao valor global e a } \\
\text { vigência. }\end{array}$ & \multirow[t]{2}{*}{$\begin{array}{l}\text { Cintra et al. (2012) Inamine } \\
\text { et al. (2012) }\end{array}$} \\
\hline & Eficiência & $\begin{array}{l}\text { Identifica fatores relacionados à } \\
\text { utilização dos recursos de forma } \\
\text { produtiva na contratação para o } \\
\text { alcance dos objetivos da } \\
\text { contratante }\end{array}$ & \\
\hline & $\begin{array}{l}\text { Conformidade } \\
\text { com as normas }\end{array}$ & $\begin{array}{l}\text { Identifica aspectos relacionados à } \\
\text { conformidade das açôes da } \\
\text { contratação com as exigências } \\
\text { estabelecidas pela Lei } 8.666 / 93\end{array}$ & Inamine et al. (2012) \\
\hline & Planejamento & $\begin{array}{l}\text { Planeja o que, quando, como, } \\
\text { onde, a quantidade, os prazos, as } \\
\text { especificações técnicas e os valores } \\
\text { que serão contratados }\end{array}$ & Magalhães et al. (2009) \\
\hline & Padronização & $\begin{array}{l}\text { É a elaboração da padronização da } \\
\text { forma de avaliação dos serviços } \\
\text { prestados pelas contratadas }\end{array}$ & Santilli et al. (2011) \\
\hline & Controle & $\begin{array}{l}\text { É o processo pelo qual os } \\
\text { administradores asseguram que os } \\
\text { recursos sejam obtidos e usados } \\
\text { eficaz e eficientemente }\end{array}$ & Franco et al. (2011) \\
\hline
\end{tabular}

Fonte: Elaborado pelos autores.

$\mathrm{Na}$ seção a seguir será tratado como são realizadas as compras de bens e as contratações de serviços pela Administração Pública e as ações da gestão de contratos relacionadas à redução dos custos dessa contratação e da execução do contrato formalizado com a contratada.

\subsection{A gestão de custos no setor público}

O objetivo da redução de custos e a eficiência nos procedimentos de compras por meio das contratações têm recebido atenção na Administração Federal (Faria et al., 2010). Para Inamine et al. (2012) o emprego da tecnologia de informação em um sistema de compras públicas pode ocasionar redução de custos nos processos de aquisição. Ching et al. (2011) entendem que o controle de custos deve ser estruturado de maneira a fornecer respostas aos questionamentos dos gestores públicos quanto à origem e ao destino de cada gasto. Henriksen et al. (2004) definem sistema de compras como sistemas de informação entre organizações que, por intermédio de seus mercados eletrônicos, permitem aos compradores e fornecedores trocar informação sobre preços e oferta de produtos rapidamente e com eficiência de custos.

No processo da contratação por meio de licitação, a Administração Pública tem basicamente dois tipos de despesas: Com a realização do processo licitatório e com a execução do contrato formalizado com a contratada. Em ambas, o gestor do contrato deverá utilizar de pesquisa de mercado como um referencial para o controle e redução dos custos, seja na etapa preparatória para a licitação ou para fazer o acompanhamento do cumprimento do contrato proveniente da licitação (Chaves, 2016). 
Para contribuir à economicidade do objeto contratado, Morais (2015) esclarece que o art. 55 da Lei n 9.666/93 estabelece como obrigatória a existência de cláusulas nos contratos celebrados entre a Administração Pública e as contratadas, nas quais contenham a descrição do objeto da contratação, do regime de execução, o preço e as condições de pagamento, os critérios, data-base e periodicidade do reajustamento de preços, dentre outras informações.

Já para o acompanhamento e a fiscalização da execução do contrato, para verificar se o bem entregue ou se o serviço está sendo prestado de acordo com o contrato, o art. 67 da Lei 8.666/93 exige que a contratante designe o fiscal do contrato. Deste modo, segundo Morais (2015), basicamente, a Administração Pública tem como obrigaçóes contratuais o pagamento e a fiscalização da contratada. $O$ processo de pagamento deverá ser precedido da apuração de que o objeto contratual foi efetivamente executado, seja com o atestado de entrega parcial ou total da obra ou produtos, seja com o atestado de prestação de serviços e quem atesta a execução do objeto é o fiscal do contrato (Morais, 2015).

Com a utilização do Pregão Eletrônico a Administração Pública tem um custo menor com a realização da licitação (Ferreira et al., 2014), modalidade que favorece a participação de um leque maior de empresas interessadas (Faria et al., 2013), contribui para uma maior competição e celeridade nas contratações públicas (Souza \& Teixeira, 2009) e proporciona a apresentação de propostas mais vantajosas para a contratante (Medeiros et al., 2014; Silveira et al., 2012).

Neste artigo, utilizam-se custos como proxy de despesas, considerando que, segundo Holanda e Machado (2010), no setor público, as despesas liquidadas serão custos, quando relativas a bens ou a serviços utilizados e consumidos no exercício corrente.

$\mathrm{Na}$ Tabela 2 encontram-se listadas as dimensões do construto gestão de custos no setor público e as variáveis associadas identificadas na literatura. Elas representam objetivos que uma eficiente gestão de contratos de uma empresa pública deve alcançar em sua gestão com as contratadas que lhes prestam serviços.

TABELA 2

Variáveis adaptadas de gestão de custo para o setor público.

\begin{tabular}{|c|c|c|c|}
\hline Construto & $\begin{array}{l}\text { Dimensões } \\
\text { Custeio }\end{array}$ & $\begin{array}{l}\text { Variáveis } \\
\text { É a identificação, a apropriação dos } \\
\text { custos e a análise dos elementos de } \\
\text { custeio da contratação dos serviços }\end{array}$ & $\begin{array}{l}\text { Referências } \\
\text { Martinez e Filho } \\
\text { (2011) }\end{array}$ \\
\hline \multirow{3}{*}{$\begin{array}{l}\text { Gestão de } \\
\text { Custo }\end{array}$} & Eficiência & $\begin{array}{l}\text { Melhoria dos resultados da contratante } \\
\text { em decorrência da contratação dos } \\
\text { servicos }\end{array}$ & Verbeeten (2011) \\
\hline & Informação & $\begin{array}{l}\text { A relevância, utilidade, oportunidade e } \\
\text { compreensibilidade da informação dos } \\
\text { custos contratação dos serviços das } \\
\text { contratadas }\end{array}$ & Machado et al, (2012) \\
\hline & Finalidade & $\begin{array}{l}\text { Prestação de serviços com o menor } \\
\text { custo, mas com qualidade e } \\
\text { lucratividade }\end{array}$ & Vila (2010) \\
\hline
\end{tabular}

Como o objetivo deste artigo é identificar variáveis relacionadas a uma eficiente gestão de contratos que conduzem uma empresa pública à redução de custos e à melhoria da qualidade dos serviços prestados pelas empresas contratadas, na próxima seção será abordada a qualidade de serviço. 


\subsection{Qualidade de serviço}

Entre as tentativas de se explicar o que é serviço, Pinheiro e Tigre (2015), baseando-se no trabalho de Miles (2008), indicam duas características que são comuns nos serviços: (a) Intangibilidade: significa que os resultados do serviço tipicamente envolvem transformações no estado de determinadas entidades, que podem ser artefatos (produtos materiais), pessoas (ou outros organismos, como animais) ou dados (símbolos); (b) Interatividade: reflete a necessidade de presença e participação do cliente em muitos processos de serviços, onde há casos compreendendo seu envolvimento ativo e conjunto com a empresa provedora.

Para o conceito de qualidade de serviço, Novaes et al. (2015) expõem, no contexto da Administração Pública como a contratante, o conceito de qualidade como sendo "conformidade com as especificações", que é o mais adequado em função da exigência às contratadas para prestarem os serviços em observância aos artigos da lei (Mendes \& Biasi, 2011).

Adil et al. (2013) propõem cinco dimensões para avaliar a qualidade de serviços: Confiabilidade, responsividade, garantia, tangíveis e empatia. No mesmo sentido, Freitas (2005) defende a necessidade do estabelecimento de Indicadores de Qualidade (IQ) por parte da empresa para avaliar a qualidade dos serviços oferecidos aos clientes e cita os Indicadores de Qualidade Subjetivos (IQS), que estão intimamente relacionados com a avaliação da qualidade dos serviços através da captação do grau de satisfação dos clientes: Cortesia, credibilidade e segurança são exemplos e os Indicadores de Qualidade Objetivos (IQO) são empregados na avaliação, no controle das atividades e dos processos.

A relação entre a gestão de contratos e a qualidade é ressaltada por Almqvist (2001), para o qual o fenômeno "gestão por contrato" tem como finalidade ajudar a formar a base para a gestão da qualidade e os objetivos da atividade do comprador. O autor afirma ainda que o contrato se tornou uma metáfora para captar a mudança nos processos de gestão e de controle dentro da organização. Já no contexto específico da Administração Pública, o art. 6 da Lei no 8.666/93 considera serviço como:

Toda atividade destinada a obter determinada utilidade de interesse para a Administração, tais como: Demolição, conserto, instalação, montagem, operação, conservação, reparação, adaptação, manutenção, transporte, locação de bens, publicidade, seguro ou trabalhos técnico-profissionais (Lei Federal nº 8.666/93, 1993).

Quanto às caraterísticas e especificações técnicas dos serviços que serão contratados, esse mesmo art. 6, normaliza a elaboração e a utilização do projeto básico para as etapas do processo licitatório, da contratação e da fiscalização da execução do contrato. A área gestora do contrato, servindo-se de apoio técnico de especialistas de outras áreas da instituição (caso seja necessário), elabora o projeto básico e o envia contido em um processo administrativo à Comissão Permanente de Licitação, que realiza o certame licitatório e, após selecionar a empresa vencedora, devolve o processo à área gestora para formalizar a contratação e realizar a fiscalização do contrato até o fim de sua vigência (Morais, 2015; Vieira, 2014).

Os critérios para avaliação contínua da qualidade do serviço realizado pela contratada devem estar descritos nas cláusulas contratuais, conforme o projeto básico. Na prestação do serviço, caso ocorra inobservância a alguma cláusula contratual, o fiscal do contrato deverá notificar a contratada com vistas à ajuste de conduta, de modo que o serviço passe (ou volte) a ser executado em completa concordância com o estabelecido no contrato (Morais, 2015; Vieira, 2014).

A Tabela 3 apresenta as dimensões do construto qualidade de serviço e as variáveis correlacionadas identificadas na literatura. Elas representam objetivos que uma eficiente gestão de contratos de uma empresa pública deve alcançar em sua gestão com as contratadas, que lhes prestam serviços, no sentido de efetivar ações que as levem melhorar a qualidade dos serviços. 
Tabela 3 Variáveis adaptadas de qualidade de serviço.

\begin{tabular}{|c|c|c|c|}
\hline \multirow[t]{2}{*}{ Construto } & Dimensões & Variáveis & Referências \\
\hline & $\begin{array}{l}\text { Indicador de } \\
\text { Qualidade } \\
\text { Objetivo }\end{array}$ & $\begin{array}{l}\text { Prestação do serviço conforme } \\
\text { descrito no contrato }\end{array}$ & Freitas (2005) \\
\hline \multirow{3}{*}{$\begin{array}{l}\text { Qualidade } \\
\text { do serviço } \\
\text { das } \\
\text { contratadas }\end{array}$} & $\begin{array}{l}\text { Indicador de } \\
\text { Qualidade } \\
\text { Subjetivo }\end{array}$ & $\begin{array}{l}\text { Grau de satisfação dos } \\
\text { empregados com a prestação do } \\
\text { serviço pela contratada }\end{array}$ & Freitas (2005) \\
\hline & Confiabilidade & $\begin{array}{l}\text { E a capacidade de executar o } \\
\text { serviço conforme contratado }\end{array}$ & $\begin{array}{l}\text { Adil et al. (2013), Parasuraman } \\
\text { et al. (1988) }\end{array}$ \\
\hline & Conformidade & $\begin{array}{l}\text { Conformidade com as } \\
\text { especificaçốes do projeto básico e } \\
\text { cláusulas contratuais }\end{array}$ & Novaes et al (2015) \\
\hline
\end{tabular}

Fonte: Elaborado pelos autores.

$\mathrm{Na}$ literatura abordada nas seções anteriores foi exposto, no contexto da Administração Pública, o que a Lei 8.666/93 estabelece para que a atividade de gestão de contratos realize no processo de contratação e de execução do contrato firmado com empresa para lhe prestar serviço, mas não foi identificada como essa gestão poderá reduzir as despesas nas etapas da contratação e na de execução do contrato e na melhoria da qualidade dos serviços das contratadas. Para suprir essa lacuna, este trabalho tem por objetivo identificar as variáveis relacionadas a uma eficiente gestão de contratos que conduzem uma empresa pública à redução de custos com a contratação, com a execução do contrato e com a melhoria da qualidade dos serviços prestados pelas empresas contratadas. Esta pesquisa focou nos constructos "gestão de contratos", "redução de custos" e "melhoria da qualidade do serviço" porque, conforme Magalhães et al. (2009), a eficiente gestão de contratos é condição indispensável para que os contratos tenham características de viabilidade assegurada, que tem seus efeitos na redução dos custos nos processos de contratação (Freitas \& Maldonado, 2013) e na melhoria da qualidade dos serviços das empresas contratadas (Medeiros et al., 2014).

$\mathrm{Na}$ próxima seção, serão apresentados os procedimentos metodológicos empregados para alcançar este objetivo.

\section{PROCEDIMENTOS METODOLÓGICOS}

Para alcançar o objetivo proposto, utilizou-se a pesquisa do tipo descritiva, qualitativa e de campo, uma vez que estudos exploratórios têm como objetivo essencial conhecer melhor fenômenos desconhecidos ou pouco estudados (Sampieri, Collado \& Lucio, 2013), sendo objeto de estudo a Empresa Brasileira de Correios e Telégrafos (ECT). Optou-se por essa empresa pelo fato de ela possuir em torno de 2.400 contratos com prestadores de serviços em todas as Regionais (2015) e por ter sido dada ampla acessibilidade aos sujeitos objeto das entrevistas e aos dados primários da empresa.

O universo foi delimitado aos gestores administrativos e operacionais de contratos das Diretorias Regionais (os nomes foram substituídos por siglas): D, I, U, X e BB, atendendo aos critérios de diversificação geográfica e do tamanho da Diretoria Regional (DR) objeto de estudo (Gaskell, 2014): A DR/D fica na

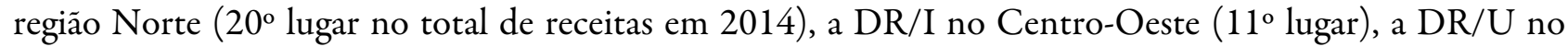
Nordeste (20 lugar), a DR/X no Sul ( $7^{\circ}$ lugar) e a DR/BB no Sudeste ( $1^{\circ}$ lugar), de acordo com o Portal do Departamento Financeiro da ECT. Os gestores administrativos são os responsáveis pelas atividades administrativas relacionadas à contratação ou à renovação (pesquisa de mercado, consulta à contratada pelo interesse ou não na renovação, bloqueio orçamentário reservando parcelas da suplementação orçamentária para custear as despesas, consulta à área jurídica e envio do processo para a área de licitação, quando for o caso de nova contratação) e os operacionais são os responsáveis pelo acompanhamento, execução do 
contrato, pelos respectivos pagamentos e pelas eventuais notificações e aplicação de sanções administrativas em decorrência de falhas cometidas pelas contratadas durante o cumprimento do contrato.

$\mathrm{O}$ instrumento de pesquisa foi entrevista semiestruturada de questões e conduzida a partir de um roteiro previamente estabelecido, contendo questões abertas, elaboradas e adaptadas com base nos trabalhos de Inamine et al. (2012), Morais (2015) e Vieira (2014). As entrevistas foram conduzidas com o objetivo de delinear como a gestão de contratos consegue conciliar a redução de custos com a contratação e com a execução do contrato e com a melhoria da qualidade dos serviços prestados pelas contratadas, buscando identificar as variáveis apontadas pelos questionados (Mozzato \& Grzybovski, 2011).

As entrevistas foram gravadas e transcritas na íntegra pelos próprios pesquisadores por meio de vídeo conferência na sala de reuniões da Sede da ECT em Natal (RN), no período de 04/08 a 09/10/2015 e duraram, em média, 44 min. Para o tratamento dos dados, adotou-se a técnica de análise de conteúdo por categoria (Bardin, 2011; Flick, 2009), com o uso do software de análise de dados qualitativos NVivo 11 (Mozzato \& Grzybovski, 2011).

O conjunto de dados obtidos dos entrevistados foi relacionado às seis categorias em três grandes temas (dimensões chave): Gestão de contratos, redução de custos e qualidade de serviços. Essas categorias são: (i) Contratação; (ii) emissão de termo aditivo; (iii) vigência do contrato; (iv) documentação regular do processo; (v) prazo de tramitação do processo e (vi) qualidade dos serviços prestados. Para analisar e validar as interrelações entre os dados coletados das entrevistas com as categorias de análise foram utilizados os coeficientes de Jaccard, de correlação de Pearson e o de Sorensen. Para definir a intensidade da correlação para esses três coeficientes foi utilizada a interpretação de Mukaka (2012).

\section{DISCUSSÃO E ANÁLISE DOS RESULTADOS}

Em relação à principal ação da gestão de contratos, as percepções dos entrevistados apontam para "providenciar para que a documentação esteja correta (a que deve constar em um processo para a contratação ou emissão do aditamento ao contrato)", "a realização da pesquisa de mercado, quando os preços propostos pela contratada são comparados com a média do mercado local” e "iniciar o processo de contratação ou da emissão do termo aditivo com antecedência”.

Conforme o NVivo 11 apresentou, ao reunir as frases e palavras dos entrevistados que foram decodificadas na árvore das ações da gestão de contratos (Fig. 1), observa-se que as expressões "controle da vigência", "vigência dos contratos" e "previstos nos manuais (a documentação constante nos processos)", possuem uma ligação bem próxima com “ações da gestão de contratos”. 


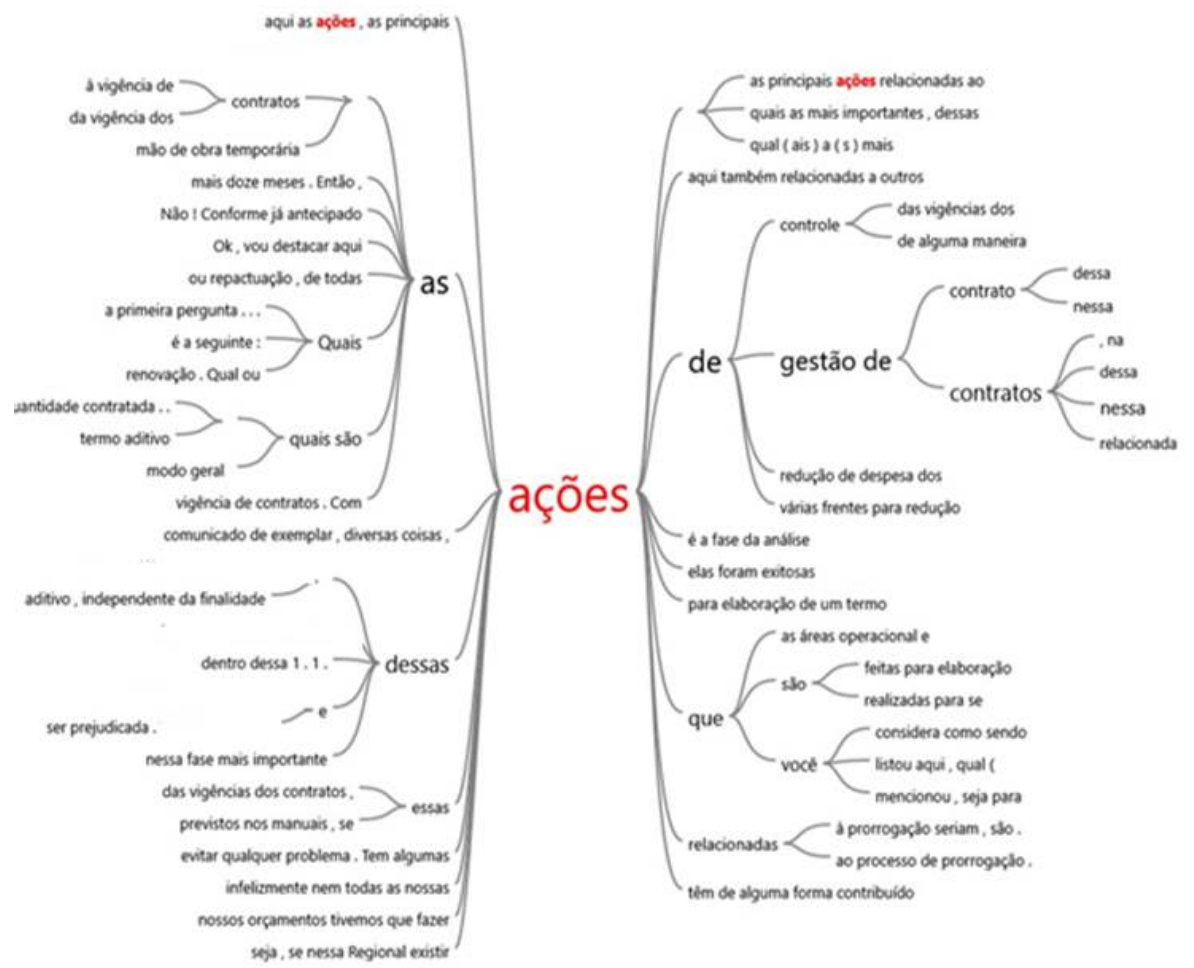

Fig. 1. Palavras ligadas às ações de gestão de contratos. Fonte: Elaboração dos autores tendo como base o NVivo 11.

Os resultados também sugerem que o controle da vigência dos contratos é um fator que pode contribuir para a redução de despesas, conforme apresentado na Fig. 2 e que a correlação que envolve a categoria (v) vigência dos contratos com a dimensão-chave redução de custos, caracteriza uma relação considerada muito alta nos coeficientes Pearson, Jaccard e Sorensen (0,946454, 0,902564 e 1, respectivamente).

Alinhado com essa perspectiva de causa e efeito entre o controle da vigência do contrato e a redução de custos, acrescenta-se que o descontrole da vigência do contrato ocasiona o aumento de custos, pois, nesse aspecto, há uma forte relação de causa e efeito, pelas respostas dos entrevistados, tendo alcançado valores muito altos nos coeficientes $(0,927917,0,929412$ e 0,963415 , respectivamente).

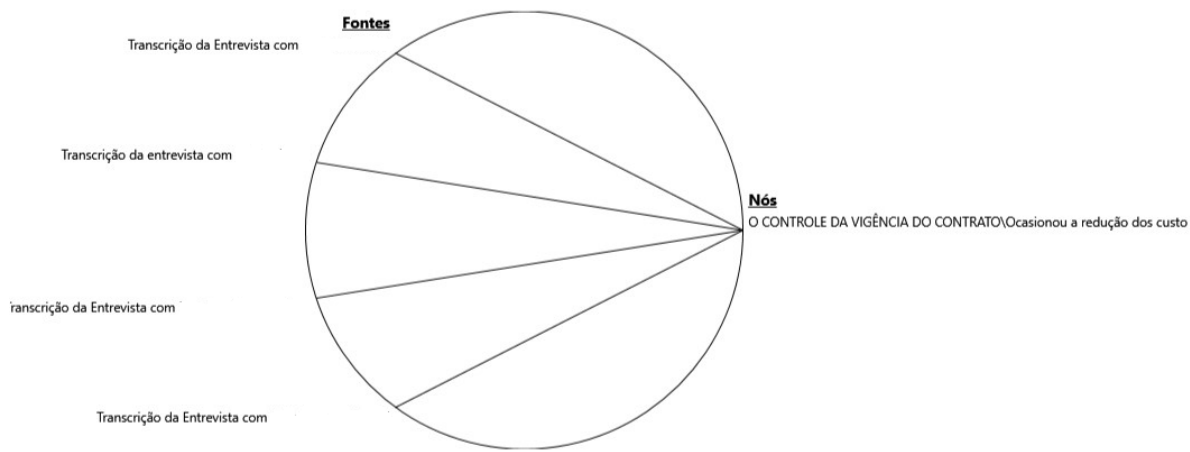

Fig. 2. Relação entre o controle da vigência do contrato e a redução de custos. ${ }^{\text {[iii] }}$ Fonte: Elaboração dos autores tendo como base o NVivo 11.

Nesta direção, os entrevistados afirmam que "uma contratação emergencial sempre é mais dispendiosa para a ECT do que aquela realizada por meio de uma licitação normal”, pois "os preços propostos pelas empresas interessadas em uma licitação emergencial geralmente são maiores”, além do mais, salientam que as despesas 
da ECT são acrescidas com "os custos de um certame licitatório, quando este poderia ter sido evitado, caso tivesse havido um controle eficiente da vigência do contrato".

Estes resultados encontram respaldo no trabalho de Inamine et al. (2012), para os quais o recurso tecnológico possibilita ao gestor controlar devidamente a vigência dos contratos e iniciar, com a antecedência necessária, os processos visando uma nova contratação ou à renovação, e assim a Administração Pública seja poupada de ter gastos desnecessários. Nesse contexto, Minuzzi-Nascimento e Tomaél (2012) destacam que a renovação do contrato precisa está prevista em cláusula contratual e, segundo Krammes (2013) e Silveira et al. (2012), contribui para a redução de despesas quando o processo de contratação ou de renovação está fundamentado em um planejamento bem elaborado.

Conforme exposto no referencial teórico, os contratos poderão sofrer alterações por meio do instrumento do termo aditivo. Desse modo, para os entrevistados, no que tange à relação de causa e efeito entre a categoria (ii) emissão de um termo aditivo e a dimensão-chave redução de custos, as respostas de todos foram convergentes, corroborando com a existência dessa relação, conforme decodificado e agrupado pelo NVivo 11 (Fig. 3).

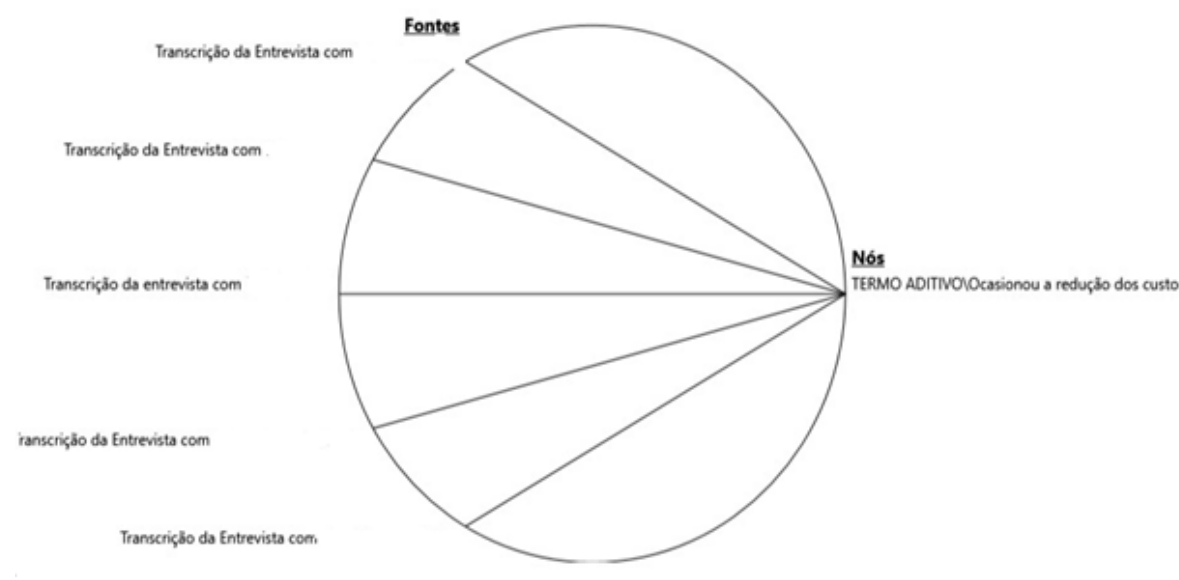

Fig. 3. Relação entre a emissão de termo aditivo e a redução de custo Fonte: Elaboração dos autores tendo como base o NVivo 11.

A Tabela 4 contém as 7 palavras mais citadas pelos respondentes (dentre as 21.855 palavras transcritas) em ordem decrescente no quantitativo de citações. Nota-se a aproximação entre as palavras "contratos", "termos aditivos", "serviço", "redução" e "despesa", sugerindo essa proximidade e o total da incidência (78,9\% entre as 7) que há uma estreita relação de causa e efeito entre a emissão de um termo aditivo e a redução de despesa, quando o objetivo do aditamento é a renovação, reajuste ou repactuação dos valores.

Tabela 4 Palavras mais frequentes pelos entrevistados.

\begin{tabular}{|c|c|c|c|}
\hline Palavra & Contagem & $\begin{array}{l}\text { Percentual ponderado } \\
\text { (\%) }\end{array}$ & Palavras similares associadas \\
\hline Contratos & 527 & 32,75 & $\begin{array}{l}\text { Contratação, contratada, contratar e } \\
\text { contrato. }\end{array}$ \\
\hline Termo aditivo & 382 & 23,74 & Termo \\
\hline Serviço & 197 & 12,24 & Serviço \\
\hline Redução & 134 & 8,33 & Redução \\
\hline Despesa & 131 & 8,14 & Despesa \\
\hline Empresa & 120 & 7,46 & Empresa \\
\hline Renovação & 118 & 7,33 & Renovar e renovada \\
\hline
\end{tabular}

Fonte: Elaborado pelos autores. 
O entrevistado da DR/I ilustrou alguns casos em que houve a redução de despesa com a emissão do termo aditivo:

[...] nós tivemos uma redução de cerca de $20 \%$ na nossa conta de vigilância neste ano, desde setembro do ano passado até este mês, com a medida de aditivos contratuais, com vistas à redução de postos. Começamos a utilizar a mão de obra já existente, principalmente em unidades que estavam sediadas em shopping centers. [...] Reduzimos a carga horária dos vigilantes de alguns postos e conseguimos com isso a redução de despesa. Nos contratos de limpeza a redução foi conseguida a partir da renegociação com os fornecedores [...]. Conseguimos recalcular os postos, diminuir a periodicidade de algumas atividades de limpeza, além da redução do número de postos contratados, quando obtivemos redução de custo [...].

Percebeu-se na narrativa dos entrevistados que a Regional consegue a redução de despesa na emissão de termo aditivo por meio de negociação com a contratada, quando, por exemplo, a ECT propõe a redução do quantitativo contratado originalmente ou quando são negociados novos preços propostos pela contratada e a contratante utiliza dos preços da pesquisa de mercado como instrumento balizador na negociação. Por esse resultado, infere-se que a emissão de um termo aditivo e o controle da vigência do contrato poderão contribuir para a redução do valor global do contrato, sendo essas duas ações pontuadas como as principais da gestão de contratos pelos entrevistados, entendimento já preconizado por Ching et al. (2011) e Rezende $e t$ al. (2010). Por outro lado, constata-se que a análise desse resultado fornece três variáveis novas, relacionadas às dimensões-chave gestão de contratos e gestão de custos e à categoria (ii) emissão de termo aditivo: "O controle eficiente da vigência do contrato pode ocasionar redução de despesa", "o controle eficiente da vigência do contrato pode evitar que a despesa aumente" e "o descontrole da vigência do contrato pode ocasionar aumento de despesa”.

Sobre a relação entre a documentação que compõe um processo de contratação ou de renovação estar regular, a qual se refere às certidões Negativas de Débito do Instituto Nacional do Seguro Social (INSS), chamadas CND, Fundo de Garantia do Tempo de Serviço (FGTS) e Fazenda Federal, dentre outras (listadas no art. 29 da Lei ${ }^{\circ}$ 8.666/93), com a redução de despesa, os entrevistados ressaltaram sobre a importância de a documentação estar completa e com dados, valores e informações corretas, para que isso possa acarretar em redução das despesas. De acordo com o entrevistado da DR/BB:

[...] como o processo é enviado à Consultoria Jurídica, [...] se o cuidado com a elaboração do processo tivesse acontecido antes de enviar, não haveria o prejuízo de o processo todo ser devolvido para a regularização, termos despesas com o retrabalho, além de podermos perder o prazo para a contratação [...].

Foram codificadas no NVivo 11 as principais expressões referentes à categoria (iv) documentação regular do processo, no mapa de árvore de palavras e destacam-se "documentação completa" "documentação correta" e "não faltando nenhuma documentação" (Fig. 4). 


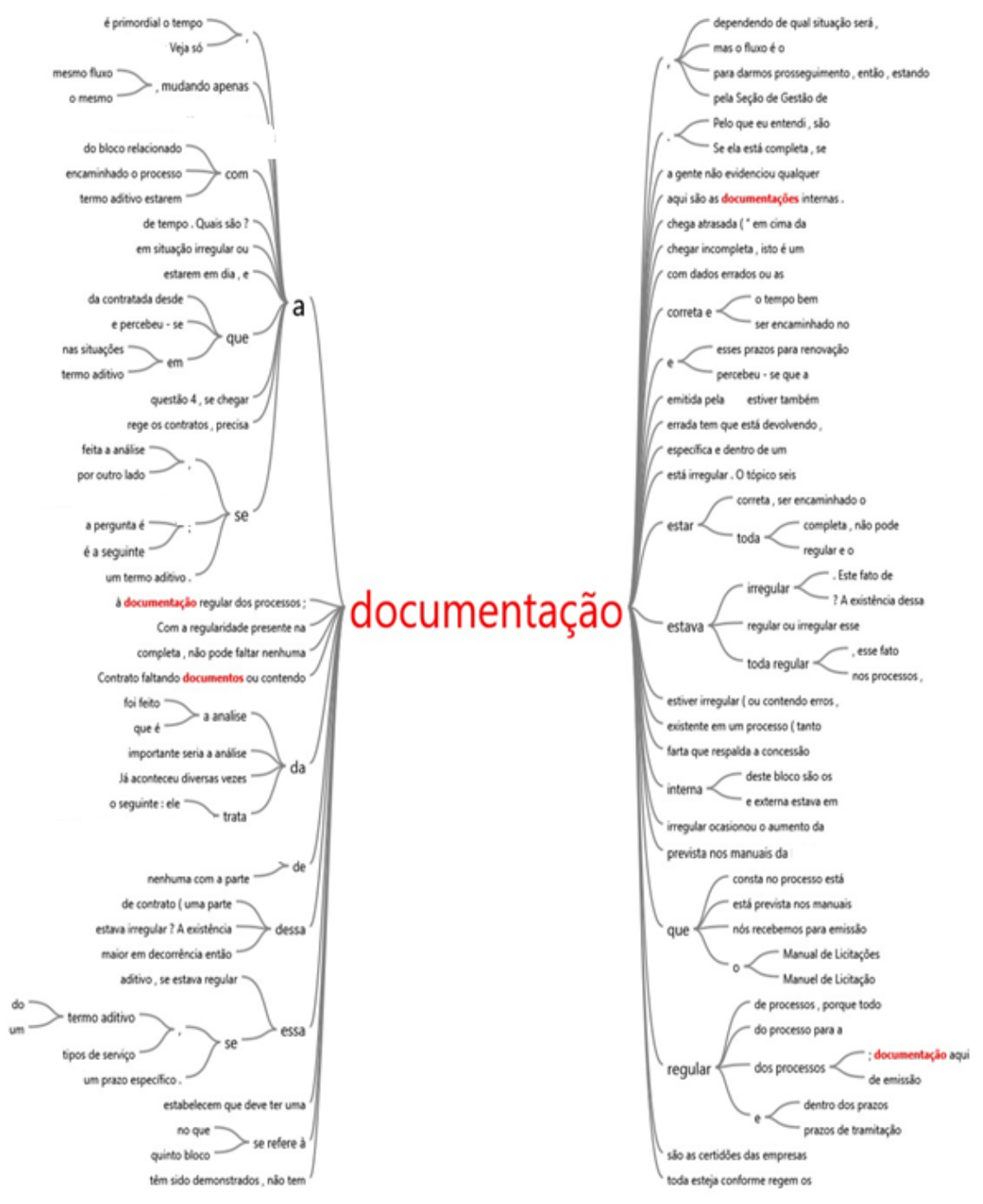

Fig. 4. Palavras ligadas à documentação regular.

Fonte: Elaboração dos autores tendo como base o NVivo 11.

Para a relação entre "documentação estando regular" com a "redução de custo", os resultados obtidos para os coeficientes Pearson e Jaccard são considerados baixos (0,332517 e 0,363636, respectivamente), enquanto que para o coeficiente de Sorensen é moderado (0,533333). Por outro lado, as expressões codificadas como "documentação irregular", "faltando documento" e "dados errados", associadas com o "aumento de custo", apresentaram a correlação máxima (1, nos três coeficientes).

Desta forma, foi possível identificar três variáveis novas, as quais não foram abordadas na literatura estudada: "A documentação que faz parte do processo de emissão de um termo aditivo, estando regular, pode ocasionar redução de despesa", "a documentação que faz parte do processo de emissão de um termo aditivo, estando regular, pode evitar que a despesa aumente" e "a documentação que faz parte do processo de emissão de um termo aditivo, estando irregular, pode ocasionar aumento de despesa”, estando relacionadas à categoria (iv) documentação regular do processo e às dimensões-chave gestão de contratos e gestão de custo.

$\mathrm{Na}$ questão referente ao cumprimento do necessário prazo de antecedência para iniciar o processo de contratação ou das alterações contratuais, se esse fato tem reflexos na redução de custo, os resultados demonstram que os respondentes afirmaram, de forma consentânea, que sim (Fig. 5). Um exemplo é o entrevistado da DR/X que reforça essa percepção, dizendo que, se o processo para se elaborar um aditamento 
contratual for feito com antecedência não reduzir despesa, pelo menos evitará que haja aumento. Em contrapartida, o entrevistado da DR/D expôs que o descumprimento do prazo para começar a emissão do termo aditivo poderá gerar um aumento de despesa por causa da provável necessidade da abertura de um processo licitatório emergencial.

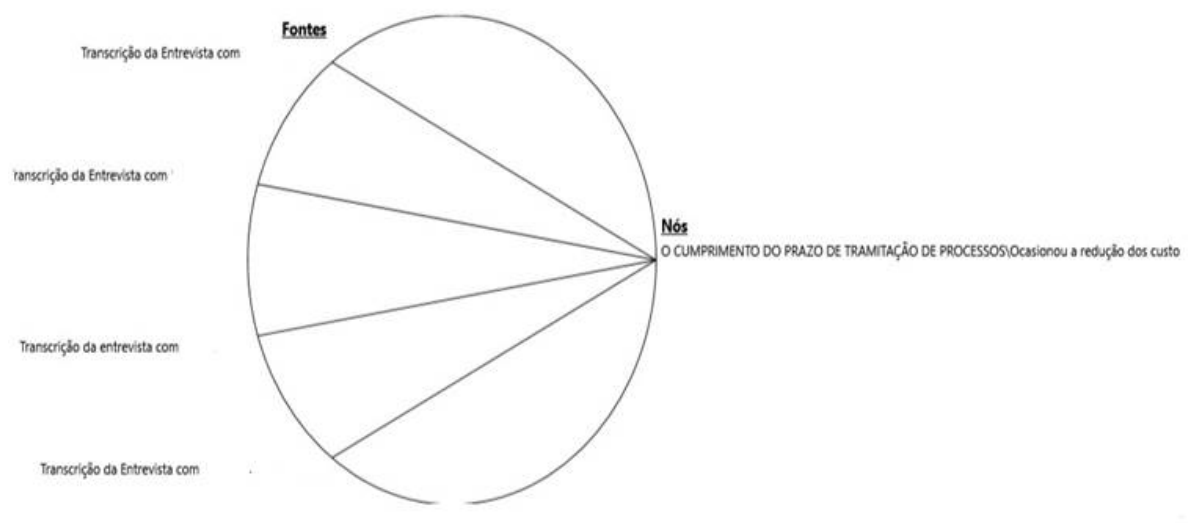

Fig. 5. Concordância dos entrevistados sobre o cumprimento dos prazos Fonte: Elaboração dos autores tendo como base o NVivo 11.

Percebe-se que os respondentes enfatizam que, quando o processo para emissão de um termo aditivo se inicia com antecipação de tempo, "possibilita que seja realizada uma bem-sucedida pesquisa de mercado", com o objetivo de "negociar a redução dos preços propostos pela contratada", para que, se ao menos não conseguir a redução, que pelo menos, evite que eles aumentem, bem como, para abster-se de despesas que são dispensáveis, tais como a da "realização de um certame licitatório emergencial" e, depois, com a “contratação emergencial”, já que, geralmente, as "contratações emergenciais acontecem com os preços dos serviços superiores aos anteriores". Os coeficientes Pearson, Jaccard e Sorensen apresentaram valores muito altos $(0,963771,1$ e 1 , respectivamente) mostrando uma forte relação de causa e efeito entre as variáveis "emissão de termo aditivo com antecedência" e "redução de despesa".

$\mathrm{Na}$ análise das respostas relacionadas com a questão "Se ocorreu o descumprimento do prazo para emissão de um termo aditivo, esse fato ocasionou em aumento de despesa”, todos os coeficientes apresentaram o nível de correlação máximo (o índice 1 nos três). Neste contexto, a relação entre o cumprimento dos prazos e a redução de despesas é apontada no estudo de Gouvêa et al. (2015), que aponta a importância da contratante de planejar e executar as etapas da gestão de contratos e no de Vieira (2014), o qual defende a necessidade do gestor de controlar a vigência do contrato e de iniciar, com a devida antecedência, o processo de renovação ou uma nova contratação.

Ao longo das entrevistas foi possível elencar três variáveis novas: "O cumprimento do prazo de tramitação do processo de emissão de um termo aditivo pode ocasionar a redução da despesa", "o cumprimento do prazo de tramitação do processo de emissão de um termo aditivo pode evitar que a despesa aumente" e "o descumprimento do prazo de tramitação do processo de emissão de um termo aditivo pode ocasionar o aumento da despesa".

Finalmente, em relação à melhoria na qualidade dos serviços prestados pela contratada, como consequência da emissão de um aditamento, os respondentes unanimemente negaram existir essa relação, pois, no entendimento deles "a qualidade da prestação do serviço está associada com uma eficiente fiscalização do contrato durante toda sua vigência”. Nesta perspectiva, o entrevistado da DR/I expôs que na sua Regional, a qualidade do serviço é avaliada periodicamente de acordo com os padrões estabelecidos no contrato e é uma das causas imprescindíveis para emissão do termo aditivo visando à renovação, sendo a outra que "os novos preços propostos se situem na média do mercado”. 
A análise de conteúdo da categoria (vi) qualidade dos serviços prestados e sua relação com as dimensõeschaves gestão de contratos e qualidade de serviços, pôde apontar causas do aumento da qualidade dos serviços prestados pelas contratadas: "Fiscalização eficiente do gestor operacional” (DR/U e I), "inclusão de cláusula contratual, condicionando a renovação do contrato com a qualidade do serviço" (DR/I) e, quando um contrato é encerrado ou emitido um termo de distrato e que "a nova contratada passa a oferecer um serviço de melhor qualidade" (DR/BB, D e I), conforme apresentado na Fig. 6. Esses resultados geraram a variável "capacidade de executar o serviço conforme o prometido", já exposta nos estudos de Adil et al. (2013) e Parasuraman et al. (1988). Nessas pesquisas, os autores defendem que um dos fatores que contribuem para que uma empresa ofereça um serviço de qualidade é de ela possuir capacidade de executar o serviço de acordo com o prometido (ou com o que está previsto no contrato).

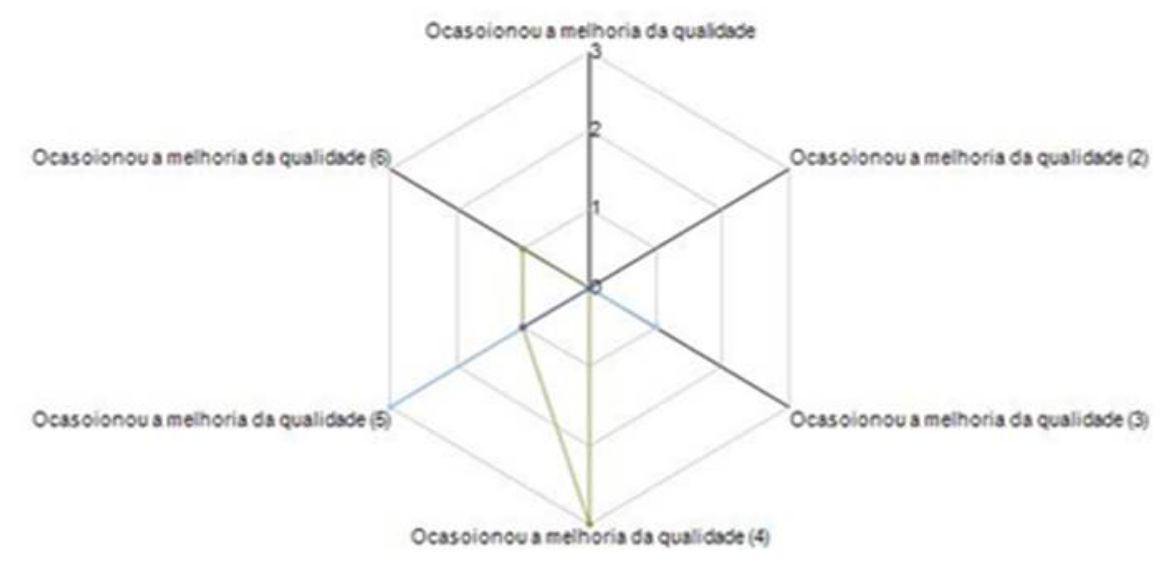

Fig. 6. Relação entre a melhoria da qualidade do serviço com a emissão do termo aditivo. Fonte: Elaboração dos autores tendo como base o NVivo 11.

A Fig. 7 apresenta as citações dos entrevistados relacionadas às categorias: (i) Contratação, (ii) emissão de termo aditivo, (iii) vigência do contrato, (iv) documentação regular do processo, (v) prazo de tramitação do processo e (vi) qualidade dos serviços prestados, no contexto das três dimensões-chave: Gestão de contratos, redução de custos e qualidade de serviços. Nota-se que as citações referentes às categorias "vi" e "v" receberam maior incidência de citações, confirmando os altos valores encontrados nos coeficientes Pearson, Jaccard e Sorensen. 


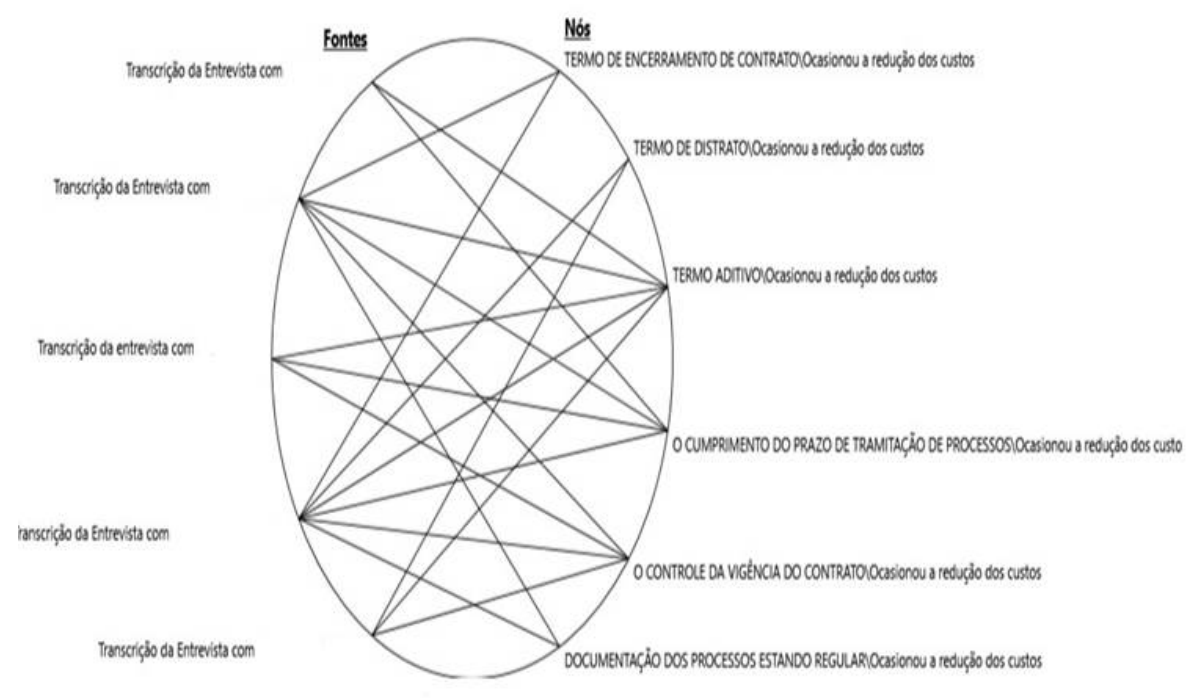

Fig. 7. Relação de causa e efeito por

\section{CONSIDERAÇÕES FINAIS}

Os resultados evidenciaram que a gestão de contratos da Administração Pública pode conduzir à redução de custos com a contratação e com a execução do contrato com a contratada e, também, à melhoria da qualidade do serviço que lhe é prestado, por meio do controle eficiente da vigência do contrato, pelo cumprimento do prazo de tramitação dos processos administrativos e quando a documentação dos mesmos, seja para iniciar a licitação ou aplicar alteração contratual, estiver regular.

A análise de conteúdo das entrevistas identificou nove novas variáveis (Tabela 5), relacionadas às dimensões Controle Eficiente da Vigência do Contrato, Prazo de Tramitação dos Processos e Documentação do Processo Estando Regular, pertencentes ao construto Gestão de Contratos.

$\mathrm{O}$ controle eficiente da vigência dos contratos significa que, com a devida antecedência, serão providenciados os documentos necessários para a renovação dos contratos ou para uma nova contratação (pesquisa de mercado, consulta à contratada pelo interesse ou não na renovação, coleta das certidões exigidas, tais como a de Negativas de Débito do INSS [CND], FGTS e Fazenda Federal, bloqueio orçamentário para provisionamento de recursos para custeamento das despesas e consulta à área jurídica). Essas providências poderão acarretar redução de despesas ou não contribuir para que elas aumentem. Todavia, um ineficiente controle da vigência provavelmente causará aumento de despesa. Associado ao controle da vigência estão as dimensões "Prazo de tramitação dos documentos" e "Documentação do processo estando regular", pois os processos tramitam entre diversas áreas (Administrativa, Operacional, Financeira, Jurídica e Licitatória), que consomem um tempo relativo e os mesmos necessitam conter os documentos exigidos por lei (listados no início deste parágrafo), de modo que a Gestão de Contratos com o controle da vigência dos contratos, poderá iniciar a tramitação dos processos de renovação ou de nova contratação, com a precedência adequada e que terá reflexos no prazo de tramitação dos processos e na qualidade das peças que compóem os documentos. 
TABELA 5

Novas variáveis identificadas nas entrevistas.

\begin{tabular}{|c|c|c|}
\hline Construto & Dimensão & Variável nova \\
\hline & $\begin{array}{l}\text { Controle eficiente da } \\
\text { vigência do contrato }\end{array}$ & $\begin{array}{l}\text { o controle eficiente da vigência do contrato pode } \\
\text { ocasionar redução de despesa } \\
\text { o controle eficiente da vigência do contrato pode } \\
\text { evitar que a despesa aumente } \\
\text { o descontrole da vigência do contrato pode ocasionar } \\
\text { aumento de despesa }\end{array}$ \\
\hline & $\begin{array}{l}\text { Prazo de tramitação dos } \\
\text { processos }\end{array}$ & $\begin{array}{l}\text { o cumprimento do prazo de tramitação do processo } \\
\text { de emissão de um termo aditivo pode ocasionar a } \\
\text { redução da despesa } \\
\text { o cumprimento do prazo de tramitação do processo } \\
\text { de emissão de um termo aditivo pode evitar que a }\end{array}$ \\
\hline $\begin{array}{l}\text { Gestão de } \\
\text { contratos }\end{array}$ & & $\begin{array}{l}\text { despesa aumente } \\
\text { o descumprimento do prazo de tramitação do } \\
\text { processo de emissão de um termo aditivo pode } \\
\text { ocasionar o aumento da despesa }\end{array}$ \\
\hline & $\begin{array}{l}\text { Documentação do } \\
\text { processo estando regular }\end{array}$ & $\begin{array}{l}\text { A documentação que faz parte do processo de } \\
\text { emissão de um termo aditivo, estando regular, pode } \\
\text { ocasionar redução de despesa } \\
\text { A documentação que faz parte do processo de } \\
\text { emissão de um termo aditivo, estando regular, pode } \\
\text { evitar que a despesa aumente } \\
\text { A documentação que faz parte do processo de } \\
\text { emissão de um termo aditivo, estando irregular, pode } \\
\text { ocasionar aumento de despesa }\end{array}$ \\
\hline
\end{tabular}

Em relação às implicações gerenciais, este trabalho apresenta eficácia prática, pois seus achados justificam a adoção de estratégias de melhoria da eficiência da gestão dos contratos, entre elas a promoção de um hábil controle na vigência dos contratos, a observância dos prazos de tramitação dos processos e o cuidado na elaboração dos documentos que compõem um processo administrativo.

Outro aspecto relevante é que, conforme demonstrado pelos resultados deste estudo e fundamentado no referencial teórico, uma eficiente gestão de contratos tem potencial para ter impactos na redução dos custos com a contratação e com a execução do contrato com as empresas contratadas e na melhoria qualidade dos serviços prestados por elas à uma empresa pública. Mesmo se tratando de variáveis identificadas nos dados qualitativos, as quais são relacionadas à gestão de contratos no contexto dos Correios e considerando a existência de outros fatores que interferem nesse tipo de gestão (cultura organizacional, capacitação técnica do quadro de funcionários e natureza da atividade desenvolvida pelo órgão público, dentre outros), presumese que esta pesquisa poderá ter uma certa implicação estendida para outros entes públicos, fazendo-se, evidentemente, as devidas adaptações, em razão de que todos estão sujeitos às normas da Lei 8.666/1993 (ver a Nota de Fim n ${ }^{\circ} 1$ ) e, por isso, os processos para contratação ou renovação dos contratos são relativamente semelhantes, uma vez que, conforme Moreira e Caleffe (2008) afirmam, as generalizações das pesquisas qualitativas, feitas sob a perspectiva positivista, não são mais vistas como meta final e única nas ciências sociais.

Este artigo tem como limitação o fato de seus resultados se basearem em percepções dos gestores acerca da redução de custos e da qualidade de serviço e não em valores mensurados para esses construtos. Assim, como um caminho para pesquisas futuras, sugere-se a elaboração de um modelo para mensurar o a redução de custos e a melhoria da qualidade de serviços, em decorrência da gestão de contratos, de uma empresa pública para com empresa contratada para lhe prestar serviços. 


\section{Agradecimientos}

O presente trabalho foi realizado com apoio da Coordenação de Aperfeiçoamento de Pessoal de Nível Superior - Brasil (CAPES) - Código de Financiamento 001

\section{REFERÊNCIAS}

Adil, D., Al Ghaswyneh, O. F. M., Albkour, A. M. (2013). SERVQUAL and SERVPERF: A review of measures in services marketing research. Global Journal of Management and Business Research, 13(6).

Almqvist, R. (2001). 'Management by Contract': A Study of Programmatic and Technological Aspects. Public Administratrion, 79(3), 689-706.

Andrade, F. A. (2010). Eficiência na gestão dos contratos administrativos. Jus Navigandi, 15(2572).

Bardin, L. (2011). Análise de conteúdo. ed. rev. e ampl. Lisboa: Edições 70.

Constituição da República Federativa do Brasil de 1988. (2014). [Saraiva]. (49a ed.) São Paulo: Saraiva.

Lei Federal no 8.666/93. (1993). Brasília: Diário Oficial da União.

Camargos, N., Moreira, M. (2015). Compras para a Inovação no Ministério da Saúde - no Discurso, Sim, na Licitação, Não. Contabilidade, Gestão e Governança, 18(3).

Chaves, E. (2016). Alteração de contratos administrativos: Estudo sobre vícios nos aditamentos aos contratos administrativos. Revista Controle (Online), 11(1), 211-233.

Ching, H. Y., Silveira, H. F. R. D., Freire, F. D. S. (2011). Gestão de custos na administração pública: Estudo de casos do governo da Bahia e do Banco Central do Brasil.

Cintra, R. F., Vieira, S. F. A., Junior, D. C. B., Fernandes, C. R., Baggio, D. K. (2012). Impacto da implantação de um sistema de informação gerencial na gestão de contratos públicos: O caso do hospital universitário de Dourados/ MS. Revista de Administração da Unimep-Unimep Business Journal-B2, 10(2), 28-53.

Faria, E. R., Ferreira, M. A. M., dos Santos, L. M., Ramos Silveira, S. F. (2010). Fatores determinantes na variação dos preços dos produtos contratados por pregão eletrônico. Revista de Administração Pública, 44(6), 1405-28.

Faria, E. R., Ferreira, M. A. M, Gonçalves, M. A. (2013). Avaliação dos riscos do pregão eletrônico: Uma abordagem pela Teoria da Nova Economia Institucional. Revista de Ciências da Administração, 1(1), 211-227.

Ferreira, M., Medina, S., Reis, A. (2014). Pregão eletrônico e eficiência nos gastos públicos municipais. Administração Pública e Gestão Social, 6(2), 74-81.

Flick, U. (2009). Introdução à pesquisa qualitativa. 3. ed. Porto Alegre: Artmed.

Franco, J. M., Colpo, K. D., Sudati, L. U., Lacerda, R. A. B. (2011). Análise das práticas organizacionais para um Sistema de Gerenciamento Ambiental (SGA) estudo de caso na ECT-agência de Santiago-RS. Revista de Contabilidade do Mestrado em Ciências Contábeis da UERJ, 15(2), 63-74.

Freitas, A. L. P. (2005). A qualidade em serviços no contexto da competitividade. Revista Produção Online, 5(1), 1-24.

Freitas, M. D., Maldonado, J. M. S. D. V. (2013). The electronic trading sessions and hiring of continuous services. Revista de Administração Pública, 47(5), 1265-1281.

Gaskell, G. (2014). Entrevistas individuais e grupais. In. Bauer, Martin W., Gaskell, G. (Orgs.). Pesquisa qualitativa com texto, imagem e som: um manual prático. 12. ed. Petrópolis: Vozes.

Girth (2014) What Drives the partnership decision? examining structural factors influencing public-private partnerships for municipal wireless broadband. International Public Management Journal, 17(3), 344-364.

Gouvêa, M. A., Pinto, R. L., \& Oliveira, B. (2015). Avaliação da qualidade de serviços terceirizados de intervenção em mobiliário e no layout em uma organização pública. Revista de Administração da UFSM, 8(1), 103-124.

Guerra, L. C. B. et al. (2012). Análise epistemológica da Nova Administração Pública à luz de Kuhn e Popper. Revista Eletrônica do Mestrado Profissional em Administração da UnP, 1, 43-53. 
Henriksen, H.Z., Mahnke, V., Hansen, J. M. (2004, January). Public e-procurement adoption: Economic and political rationality. In System Sciences, 2004. Proceedings of the 37th Annual Hawaii International Conference on (pp. 9pp). IEEE.

Holanda, V. B., Machado, N. (2010). Diretrizes e modelo conceitual de custos para o setor público a partir da experiência no governo federal do Brasil. Revista de Administração Pública, 44(4), 791-820.

Inamine, R., Erdmann, R. H., Marchi, J. J. (2012). Análise do sistema eletrônico de compras do governo federal brasileiro sob a perspectiva da criação de valor público. Revista de Administração, 47(1), 124-139.

Jorge, M. J., Avellar, C. M., de Melo, L. C., Pigatto, J. A. M., Batista, D. L. (2010). Indicadores de Efetividade em custo de atividades-meio no modelo de gestão para resultados: a experiência do Ipec/Fiocruz. Revista de Educação e Pesquisa em Contabilidade (REPeC), 4(2), 1-22. https://doi.org/10.17524/repec.v4i2.198

Krammes, A. G. (2013). Gerenciamento do escopo em projetos originados por meio de licitação. Revista de Gestão e Projetos, 4(3), 30.

Lewis, G., Bajari, P. (2011). Procurement Contracting With Time Incentives: Theory and Evidence. The Quarterly Journal of Economics, 126(3), 1.173-1.211. https://doi.org/10.1093/qje/qjr026

Magalhães, Y. T., das Graças Ferreira, A. M., Saraiva, L. A. S., Brasil, E. R. (2009). Competências necessárias e competências exercidas na gestão de contratos de serviços terceirizados em uma empresa do setor de mineração de Minas Gerais. Contextus-Revista Contemporânea de Economia e Gestão, 7(2), 41-52.

Medauar, O. (2015). Direito administrativo moderno. 19. ed. São Paulo: Editora Revista dos Tribunais.

Medeiros, F. S. B., dos Santos, S. X., Denardim, É. S., Abbade, E. B. (2014). A qualidade dos produtos e serviços em licitações do tipo menor preço: Um estudo em uma câmara de vereadores do Rio Grande do Sul. REGE-Revista de Gestão, 21(4), 491-508.

Mendes, R. G., Biasi, F. M. de. (2011). Lei de licitações e contratos administrativos: Incluindo legislação complementar correlata. 25. ed. rev. e atual. Curitiba: Zênite.

Miles, I. (2008). Patterns of innovation in service industries. IBM Systems Journal, 47(1), 115-128.

Minuzzi-Nascimento, L. M., Tomaél, M. I. (2012). Informação para tomada de decisão em processo licitatório para contratação de obras de engenharia na UEL. Perspectivas em Gestão \& Conhecimento, 2(2), 82-96.

Morais, A. P. A. (2015). Gestão pública em saúde: Contratos administrativos. São Luiz: EDUFMA.

Moreira, H., Caleffe, L. G. (2008). Metodologia da pesquisa para o professor pesquisador. 2. ed. Rio de Janeiro, RJ: Lamparina.

Motta, C. P. C. (2011). Eficácia nas licitações e contratos: Estrutura da contratação, concessões e permissões, responsabilidade fiscal, pregão - parcerias público-privadas. 12. ed. Belo Horizonte: Del Rey.

Motta, P. R. M. (2013). O estado da arte da gestão pública. RAE-Revista de Administração de Empresas, 53(1), 82-90.

Mozzato, A. R., Grzybovski, D. (2011). Análise de conteúdo como técnica de análise de dados qualitativos no campo da administração: Potencial e desafios. Revista de Administração Contemporânea, 15(4), 731-747.

Mukaka, M. M. (2012). A guide to appropriate use of correlation coefficient in medical research. Malawi Medical Journal, 24(3), 69-71.

Novaes, C., Lasso, S., Mainardes, E. W. (2015). Percepções de qualidade do serviço público. Revista Pensamento Contemporâneo em Administração, 9(1), 107-123.

Parasuraman, A., Zeithaml, V. A., Berry, L. L. (1988). Servqual: A multiple-item scale for measuring consumer perc. Journal of retailing, 64(1), 12.

Persson, E., da Silveira Porto, R., Lavor, A. K. C. (2016). O RDC como nova aposta da administração pública gerencial em licitações: O caso da Universidade Federal de Santa Catarina. Revista do Serviço Público, 67(1), 56-85. 9

Pinheiro, A. O. M., Tigre, P. B. (2015). Proposta de investigação sobre o uso de software no suporte à inovação em serviços. Revista de Administração de Empresas, 55(5), 578-592.

Rezende, F., Cunha, A., Cardoso, R. L. (2010). Custos no setor público. Revista de Administração Publica-RAP, 44(4), 789-791. 
Rkein, A., Andrew, B. H. (2012). Public sector commercial orientation and the social contract. Pacific Accounting Review, 24(3), 292-313.

Sampieri, R. H., Collado, C. F., \& Lucio, M. del P. B. (2013). Metodologia depesquisa. 5. ed. Porto Alegre: Penso, 2013.

Santilli, E. B., Luciano, E. M., \& Testa, M. G. (2011). Gestão de contratos e sua contribuição para a Governança de Tecnologia da Informação: Um estudo de caso em uma indústria brasileira de grande porte. Artigo apresentado no III Encontro de Administração da Informação ANPAD (EnADI). Porto Alegre, RS.

Sharf, E. R., Soriano-Sierra, E. J. (2006). A administração pública e a decisão de compra técnica de performance: Um estudo no setor de segurança pública. Gestão \& Regionalidade (Online), 22(64).

Silveira, E. S., Cintra, R. F., Vieira, S. F. A., Lopes, A. C. V. (2012). Análise do processo de compras do setor público: o caso da Prefeitura Municipal de Dourados/MS. Revista de Administração IMED, 2(3), 158-171.

Souza, W., Teixeira, A. J. C. (2009). Um estudo sobre a viabilidade de implantação do pregão eletrônico e uma contribuição na apuração dos resultados nos processos licitatórios. Revista de Educação e Pesquisa em Contabilidade (REPeC), 2(2), 75-94.

Vieira, A. L. (2014). Gestão de contratos administrativos. Revista de Contratos Públicos-RCP, Belo Horizonte, ano, $3,9-32$.

Vila, M. (2010). Competir con estrategias low cost. Revista de Contabilidad y Dirección, 11, 25-38.

\section{Notas}

1 As entrevistas foram realizadas em 2015, quando a empresa Correios ainda estava no âmbito da Lei 8.666/93, por isso que a Lei 13.303/2016 não foi citada, uma vez que a mesma passou a vigorar a partir de 30/06/2016.

2 Fez-se a busca de artigos nas citadas bases de pesquisa, para o período indicado, porque a finalização deste estudo deuse no início de 2018.

3 Na sequência de cima para baixo: Transcrição da entrevista com a DR/D, I, U, BB e X.

4 Na sequência de cima para baixo: Transcrição da entrevista com a DR/X, D, I, U e BB.

5 Na sequência de cima para baixo: Transcrição da entrevista com a DR/X, D, I, e U.

\section{BY-NC-ND}

